\title{
Optimization of the Digital Receiver Testing Process: A Case Study
}

\author{
Bruno Souza Pinto ${ }^{1}$, Ewerton da Silva Monteiro ${ }^{2}$, Raimundo Nonato Alves da Silva ${ }^{3}$, Paola Souto Campos ${ }^{4}$, Greyce \\ dos Santos Rodrigues ${ }^{5}$, Vanise dos Santos Rodrigues ${ }^{6}$
}

1,2,3,4 Centro Universitário do Norte (UNINORTE). Manaus. Amazonas. Brasil

${ }^{5,6}$ Instituto de Tecnologia e Educação da Amazônia (ITEGAM). Manaus. Amazonas. Brasil.

Email:pintobruninho377@gmail.com,ewertonm56@gmail.com,raimundo.nonato.silva@ gmail.com,paola.campo@uninorte.com.br, greyce.gsr@gmail.com,vanise_santosrodrigues@hotmail.com.

Received: October $11^{\text {th }}, 2016$

Accepted: November, $17^{\text {th }}, 2016$

Published: December $22^{\text {th }}, 2016$

Copyright $(2016$ by authors and Institute of Technology Galileo of Amazon (ITEGAM). This work is licensed under the Creative Commons Attribution International License (CC BY 4.0).

http://creativecommons.org/licenses/by/4.0/ (c) (i) (2) Ope Acests

\section{ABSTRACT}

In view of the current scenario found in the factory as to the effective removal of the printed circuit board from the production conveyor and realizes the connection of the HDMI, RCA, power and USB connector cables manually to perform the receiver test, taking into account View the time required to make the cable connections considered high within the current context. Considering the time wasted on the connection of the cables to test the receiver, this case study seeks to implement a solution to make the connections more efficiently optimizing the test process. This research has as its aim to seek an improvement for the digital receiver manufacturing industry in the industrial center of Manaus due to the need to maximize productivity and especially the increase of cost benefit for the company in which the case study was carried out.

Keywords: Optimization, productivity, digital receiver, chrono-analysis, ergonomics.

Otimização do Processo de Testes de Receptor Digital: Um Estudo de Caso

\section{RESUMO}

Diante do cenário atual encontrado no âmbito fabril quanto a efetivação de retirada da placa de circuito impresso da esteira de produção e realiza a conexão dos cabos HDMI, RCA, de alimentação elétrica e conector USB de forma manual para realizar o teste do receptor, tendo em vista o tempo necessário para fazer as conexões dos cabos considerado elevado dentro do contexto atual. Considerando o desperdício de tempo quanto a conexão dos cabos para teste do receptor, este estudo de caso busca implementar uma solução para realizar as conexões de forma mais eficiente otimizando o processo de teste. Essa pesquisa tem como relevância buscar uma melhoria para indústria de fabricação de receptor digital no polo industrial de Manaus haja vista a necessidade da maximização da produtividade e principalmente o aumento de custo benefício para a empresa na qual foi realizado o estudo de caso.

Palavras Chaves: Otimização, produtividade, receptor digital, cronoanálise, ergonomia.

\section{INTRODUÇÃO}

No cenário econômico atual, aperfeiçoar o desempenho é uma preocupação constante para qualquer empresa que queira se estabelecer e sobreviver no mercado de forma competitiva, enfrentando a grande concorrência e a exigência cada vez maior por parte dos seus clientes.
A preocupação com a produtividade teve início nas primeiras décadas do séc. XX, quando os estudos sobre o tema começaram a surgir, tendo Taylor como um de seus maiores expoentes, através da chamada Administração Científica, abordando os benefícios de estudar a produção, a partir da observação dos processos de trabalho [1]. 
No cenário econômico atual, aperfeiçoar o desempenho é uma preocupação constante para qualquer empresa que queira se estabelecer e sobreviver no mercado de forma competitiva, enfrentando a grande concorrência e a exigência cada vez maior por parte dos seus clientes.

A preocupação com a produtividade teve início nas primeiras décadas do séc. $\mathrm{XX}$, quando os estudos sobre o tema

começaram a surgir, tendo Taylor como um de seus maiores expoentes, através da chamada Administração Científica, abordando os benefícios de estudar a produção, a partir da observação dos processos de trabalho [1].

O setor de Engenharia nas indústrias é o responsável por viabilizar a produção através dos conhecimentos de administração, finanças, economia e engenharia através da atuação na implantação, planejamento, operação e melhoria dos processos produtivos, integrando mão de obra, equipamentos e matéria prima, com o intuito de reduzir os desperdícios e aumentar a lucratividade [2]. O setor de Engenharia nas indústrias é o responsável por viabilizar a produção através dos conhecimentos de administração, finanças, economia e engenharia através da atuação na implantação, planejamento, operação e melhoria dos processos produtivos, integrando mão de obra, equipamentos e matéria prima, com o intuito de reduzir os desperdícios e aumentar a lucratividade [2].

A otimização de processos em uma indústria é de suma importância para garantir a empresas, a maximização da produtividade, minimizar os custos operacionais, minimizar o tempo da produção de determinado setor fabril. A otimização em processos industriais são amplamente utilizados em diversos setores. Na literatura encontram - se aplicações de otimização utilizada na indústria, cabe citar [3] que aplica o processo de otimização para avaliar o comportamento de amplificadores de radiofrequência (RF) de potência em aplicações de telecomunicações para otimizar a eficiência geral do amplificador durante o processo produtivo (de Souza Limaa, Balestrassib et al. 2010).

Em Manaus localiza-se o Distrito Industrial (DI) que é composto por empresas de diversos segmentos que movimentam a economia brasileira com a instalação de multinacionais que atuam em vários segmentos dentre os quais: O pólo de duas rodas, polo eletroeletrônico, pólo mecânico, pólo metalúrgico, pólo químico, polo plástico, dentre outros.

A preocupação com a produtividade nas empresas do DI é visto como um dos principais focos, assim também é o objetivo de qualquer empresa que desenvolve atividades voltadas a produção. Sendo assim, criar métodos que otimizem o tempo na produção, minimizem os custos de operações e proporcione um posto de trabalho ergonomicamente correto para o colaborador também é uma preocupação dos gestores das industrias [4].

O estudo de caso na engenharia de produção é definido como se um estudo de natureza empírica que investiga um determinado fenômeno, geralmente contemporâneo, dentro de um contexto real de vida, quando as fronteiras entre o fenômeno e o contexto em que ele se insere não são claramente definidas. Tratase de uma análise aprofundada de um ou mais objetos (casos), para que permita o seu amplo e detalhado conhecimento [5].

Esta pesquisa em enfoque é um estudo de caso que tem como objetivo implantar um dispositivo de teste confeccionado em material acrílico para otimizar o processo de produção de Receptor Digital, dispositivo em formato de uma gaveta que permite viabilizar de maneira mais eficiente a conexão dos cabos HDMI, RCA, CABO DE ALIMENTACÃO e USB em placas de receptores digitais, atividade essa desenvolvida anteriormente através de conexão manual visando melhorar o processo de produção para otimização do tempo versus produtividade e melhorar a ergonomia dos colaboradores de uma empresa localizada no Polo Industrial de Manaus (PIM).

\section{REVISÃO BIBLIOGRÁFICA}

\section{II.1 REVOLUÇÃO INDUSTRIAL BRASILEIRA}

Para [6] afirma que o ano de 1930 foi o marco principal da revolução nacional. Antes desse advento, o Brasil era um país preponderantemente semicolonial. Com os primeiros passos para a industrialização, iniciou-se também a marcha rumo ao desenvolvimento. Em múltiplos aspectos, as implicações de ordem econômica se sobressaíram no cenário brasileiro, dando uma guinada definitiva na História. Desenvolvimento e crise no Brasil [6].

Para [7] informa que uma novidade que também colaborou para o começo da revolução de 30 , foi o despertar da consciência nacional com a eclosão da Primeira Guerra Mundial. Acordou o Brasil do marasmo histórico vivido até então; e começou a se perceber como uma nação periférica e dependente. A renúncia a essa condição subalterna começou a ganhar corpo. Para [7] afirma que: "alguns setores da sociedade passaram a preocupar-se com a superação do atraso histórico e com a necessidade de imprimir um novo rumo ao país".

A Revolução de 1930 foi objeto de várias interpretações. Alguns a classificaram como uma revolução burguesa, outros como uma revolução das dessas médias, e outros apenas como um golpe militar. Independentemente do caráter que se lhe queira atribuir, foi certamente um ponto de inflexão na política brasileira [7].

Para [6] a maior parte da população era agrária, fora do mercado nacional, produzindo artesanalmente o necessário para a sua própria subsistência, em condições ínfimas, de modo que não se podia admitir a existência dum mercado interno. Assim, a História brasileira, depois de muito tempo permanecendo no mesmo sentido linear e sem muitas alternâncias, mudou totalmente.

\section{II.2 A IMPLANTAÇÃO DA ZFM (ZONA FRANCA DE MANAUS)}

A Zona Franca de Manaus (ZFM) foi idealizada como Porto Livre, a partir 1957. Passando-se dez anos, o Decreto-Lei ${ }^{\circ}$ 288, de 1967, reestruturando o padrão de incentivos fiscais, implementando um polo industrial, comercial e agropecuário na Amazônia.

Posteriormente, no período de 1750 a 1777, a administração do marquês de Pombal "planejou" um programa agrícola para a região e pela primeira vez foram utilizados incentivos fiscais com o objetivo de promover a atividade produtiva e implantar núcleos colonizadores. Essa iniciativa 
pioneira constituiu, nas Américas, o primeiro registro histórico no sentido de promover o desenvolvimento de uma região mediante um programa de incentivos fiscais [8].

Ressalta-se que [8], afirma que de acordo com a história, as diferenças geográficas da Amazônia e o dificil acesso e as peculiaridades regionais, constituiram-se uma das maiores barreiras encontrados pelos colonizadores no passado para definir estratégias de construção da logística da economia local.

A evolução do conflito mundial, iniciado em 1939, deu a Vargas a oportunidade de celebrar em 1943 os Acordos de Washington, onde novamente a Amazônia estava em causa, a serviço do Brasil e do esforço de guerra dos aliados. Através desses acordos. Vargas trocava a borracha da Amazônia pela tecnologia do aço. Com uma só tacada criava o Banco de Crédito da Borracha, em parceria com os americanos, estabelecendo o monopólio da compra do produto e sua entrega para os Estados Unidos através da "Rubber Development Corporation" e obtinha compromissos e empréstimos; retornava assim o processo de ocupação econômica da Amazônia por meio de um projeto de recuperação dos seringais nativos [..] [8].

Salazar comenta que sobre as mudanças ocorridas na economia da seguinte forma. Para ele uma nova realidade surgiu significativamente com o advento da II Guerra Mundial.

Sobre as conjunturas predispostas entre o Brasil e os aliados, o autor delineia a relevância do desenvolvimento através da borracha e principalmente com a parceria dos estados unidos retomando desta forma o processo econômico da Amazônia quanto a recuperação dos seringais nativos. Produto de grande valia no período áureo onde a borracha era considerada a matéria prima de grande valor considerado o ouro negro da região amazônica.

Segundo [8], com o aumento significativo da balança comercial causado pela produção da borracha amazônica, Vargas conseguiu também transformar os rumos da economia nacional:

Quanto à influência da economia gomífera para o Brasil, [8] destaca que: a Amazônia dava assim sua contribuição à criação da indústria de base da Era Vargas, com isso, possibilitando um avanço enorme do processo de industrialização do país.

Criava-se um serviço especial de saúde pública (SESP); promovia-se a modernização do sistema de transporte fluvial: ao mesmo tempo concedia- se aos aliados uma base de operações em Natal (RN) e obtinha-se como trunfo mais importante, empréstimos do governo americano que permitiam dar o passo decisivo para a implantação da indústria nacional através do domínio da tecnologia do aço e da consolidação da Companhia Siderúrgica Nacional, criada em 1941, mas com graves dificuldades de implantação por falta de capitais e tecnologia, e que em consequência dessas iniciativas iniciou a produção doméstica do aço em 1946. Tudo isso foi feito tendo como aval futuras quantidades a serem produzidas da estratégica borracha amazônica, indispensável ao esforço de guerra dos aliados e única alternativa à produção dos seringais malaios então ocupados pelos japoneses [8].

Depois da fase áurea gomífera, veio um período de crise. Mas logo surgiram novas propostas e projetos voltados à promoção do desenvolvimento da Amazônia com o ano de 1950, o Banco de Crédito da Borracha, transformou-se em Banco de
Crédito da Amazônia. Já em 1952, foi criado o Instituto Nacional de Pesquisas da Amazonia (INPA)

A criação de um conjunto de benefícios - especialmente os incentivos fiscais - por meio do projeto Zona Franca de Manaus (ZFM), estimulou a implantação de empreendimentos industriais na capital do estado do Amazonas. Inicialmente estruturados a partir de poucas e simples operações, ao longo do tempo esses empreendimentos cresceram em complexidade, resultando em visíveis impactos na dinâmica da economia local.

Sofisticação de operações e diversidade de iniciativas combinou-se para exigir da Superintendência da Zona Franca deE Manaus (SUFRAMA), autarquia federal responsável pela administração do principal conjunto de incentivos da ZFM, o desenvolvimento de competências para realizar o que na prática pode ser comparado à gestão de uma política industrial de abrangência reduzida, pelo menos no que concerne aos elementos passíveis de serem estabelecidos e influenciados localmente.

Substituição de importações, atração de fornecedores de componentes, implantação de laboratórios de desenvolvimento e indução à tomada local de decisão são alguns dos exemplos de ações implementadas que buscaram a consolidação da atividade industrial, a partir de uma maior integração vertical.

\section{II.3 PRODUTIVIDADE}

Diante do contexto produtivo que se apresenta a indústria, os últimos anos tem se constituído uma época de significativas mudanças econômicas e ao que se refere aos modelos de gestão e organização do sistema produtivo. Podemos elencar dois momentos que ilustram de forma transparente esse período dentre os quais:

A primeira grande mudança observada foi o exponencial desenvolvimento tecnológico ocorrido, tanto em termos de máquinas e equipamentos, como nas tecnologias de informação, que permitiram o planejamento e controle mais eficiente das operações industriais. A segunda grande alteração está relacionada com as transformações derivadas de novas filosofias, conceitos e metodologias de gestão de recursos humanos, que passaram a ser vistos como principal fonte de vantagem competitiva das empresas. O investimento tecnológico trouxe vários benefícios para o avanço da produtividade, na qual ajudou tanto no desenvolvimento de novas tecnologias quanto nas máquinas e equipamentos.

Pode-se afirmar que essa área da organização trata se de recrutamento, da seleção, do treinamento, do desenvolvimento, da manutenção, do controle e da avaliação dos funcionários de uma indústria.

Conforme [9], deste modo podemos considerar que a existência da área de Recursos Humanos está diretamente relacionada à melhora da efetividade dos funcionários nas empresas, implicando na melhor efetividade organizacional.

No Brasil a produtividade industrial na década de anos noventa vem numa perspectiva de compreender o processo de crescimento diante dos resultados da evolução da produtividade industrial resultados esse atribuído aos problemas de recessão econômica no início dos anos oitenta [10][11], seus efeitos sobre a taxa de câmbio propiciaram mudanças na estrutura de 
desenvolvimento do país, com sensíveis ganhos principalmente na produtividade industrial.

Diante do atual cenário industrial e principalmente competitivo as indústrias buscam novas ferramentas que possibilitem a obtenção de vantagens e desenvolvimento nos sistemas produtivos.

Desta forma a produtividade apresenta se como à capacidade em que a indústria desenvolve o "produto" no seu processo produtivo onde não se trata especificamente ao processo de produção compreendendo as principais etapas dentro deste processo visando sua funcionalidade quanto sua quantidade, qualidade, relação com fornecedores, logística de suprimentos, dentre outros. Para [12] compreende que o fator de produtividade depende consideravelmente da mão de obra de modo que a produtividade aumenta e/ou diminui de acordo com o ritmo do operador sendo distribuídas em três partes: acima do normal (é quando um operador trabalho em um ritmo rápido), normal (trabalhando sem muitas hesitações), e abaixo do normal (trabalhando lentamente). $\mathrm{O}$ mesmo autor afirma que:

Portanto, é o ritmo de trabalho o fator preponderante da variação da produtividade industrial sendo ele o responsável direto por uma menor ou maior quantidade de unidades produzidas por um operador em um determinado período de tempo, executando uma operação específica.

Partindo deste pressuposto a realização de qualquer tarefa é necessária certa habilidade, portanto não se pode fazer estudo de tempos com pessoas inexperientes, na cronometragem apareceriam tempos diferentes afetando a veracidade dos dados. Segundo [12] afirma que: "Um operador normal é aquele que foi selecionado, treinado e julgado apto a executar determinada tarefa. Sua idoneidade é implícita pelo fato de que recebe um salário pelo serviço. Quanto ao esforço normal e aos meios de medi-lo, a resposta é categórica, precisamos utilizar nossa capacidade inata de avaliação. Até agora, não foi encontrado instrumento melhor"

Portanto é necessário para esses estudos operadores normais, aptos a realizar a tarefa com habilidades médias, mas mesmo entre dois operadores considerados habilidosos para realização da atividade encontram-se pequenas oscilações de tempo, mas não afetam o estudo.

No que concerne a produtividade pela definição de métodos podemos mensurar a produtividade através de métodos já existentes e pode ser comparada com índice e equivalentes ao de outras empresas , metodologia comum utilizados atualmente pelas empresas como demonstra [13] na Figura 1.

Conforme o ciclo da produtividade as comparações representam os níveis de planejamento a serem atingidos tanto a curto e ao longo prazo, introduzindo melhorias realizando adequações necessárias bem como novas medidas sucessíveis de acordo com sua utilização.

$\mathrm{Na}$ atual conjuntura conceitual e metodológica a medição da eficiência do processo produtivo é determinada pela relação entre o valor adicionado (output) e os recursos que a indústria utiliza (inputs) nesse processo.

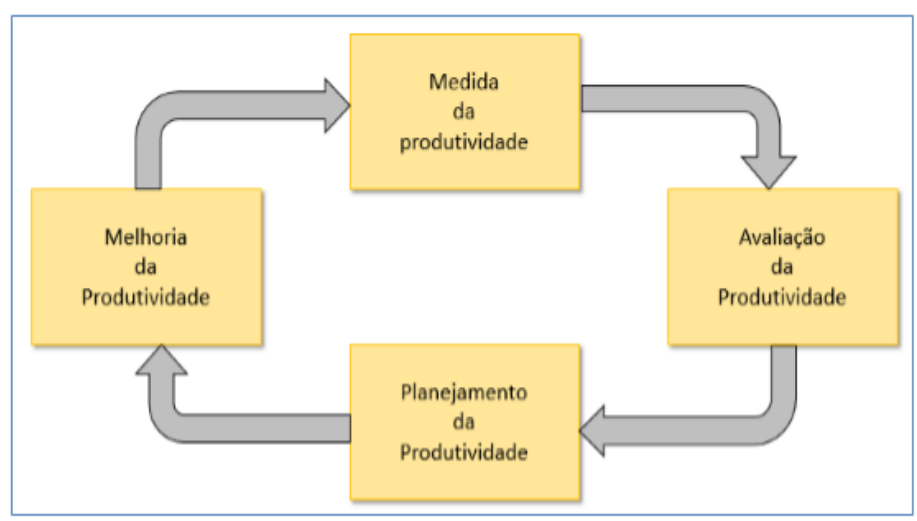

Figura 1: Ciclo da Produtividade

Fonte: [13].

\section{II.4 OTIMIZAÇÃO DE PROCESSOS}

Toda organização tem em seus critérios buscar pela constante otimização da produção e, para que essa organização sobreviva nesse cenário, ela precisa atentar-se à maximização dos lucros e minimizar os custos e para tanto, todo gestor deve estar apoiado em informações que sejam funcionáveis para que possa tomar decisões que sejam seguras e que garantam a viabilidade das organizações.

Para [14] argumenta que a otimização dos processos é direcionada à compreensão do processamento em si, a análise das perdas, e seu relacionamento com as operações subsequentes.

A Teoria das Restrições está relacionada com a análise e o balanceamento do fluxo do processo e eliminar os gargalos em um sistema de produtivo. Para [15] aponta a seguinte sequência Atividades é estabelecida;

- $\quad$ Identificar as restrições do sistema;

- $\quad$ Explorar a restrição para então subordinar todos os demais recursos a ela;

- $\quad$ Elevar a sua capacidade;

- Quando não houver mais um gargalo, retorna-se ao passo inicial até que haja uma nova sequência de gargalos.

Segundo [16] explica que a Produção Enxuta é um método onde se fabrica produto utilizando-se a eliminação de elementos que não são necessários na produção e tudo isso para que se obtenha uma redução de custos.

A lógica da Produção Enxuta para [17] afirma que as melhorias realizadas no posto de trabalho devem ser executadas quando existem operações que são restritos a correta operação do sistema de produção.

\section{II.5 PRODUÇÃO ENXUTA}

A Produção Enxuta é definia como uma forma de otimizar a produção através de vários fatores que, estando unidos, possibilitam um melhor desempenho do sistema produtivo como um todo.

Alguns desses fatores podem ser a flexibilização, a redução dos tempos de fabricação e de estoque, trabalhadores multifuncionais, diminuição das perdas e a produção em si, 
quando se tem o intuito de eliminar qualquer perda onde não se tenha valores agregados ao produto [18][19][20].

Para [13] no sistema de produção enxuto utiliza-se de diversas ferramentas e técnicas, como Kanban, Círculos da qualidade, QFD, Células de trabalho ou de produção entre outras formas integradas.

Quando se aborda sobre organização, [21] aborda a Produção Enxuta como a busca para agir nos pontos que são mais críticos e que geram maior desperdício ao sistema produtivo.

De acordo com [22], estes pontos são chamadas de "as sete perdas da produção", e estão classificadas como: Superprodução; Espera; Transporte e/ou transferência; Superprocessamento e/ou processamento incorreto; Excesso de estoque; Deslocamentos desnecessários; Defeitos.

Para os [23]: Embora a maturidade de um sistema de produção enxuta esteja associada principalmente à absorção dos princípios enxutos pela cultura organizacional, a avaliação de práticas operacionais associadas à $\mathrm{PE}$ fornece indícios acerca da implantação desse sistema.

Compreende que é um método para avaliar de maneira qualitativa a implantação das práticas da produção enxuta.

\section{II.6 GARGALO}

Na produção industrial o gargalo é um problema que limita capacidade produtiva define-se gargalo como sendo:

Gargalo é entendido como qualquer obstáculo na linha de produção que possa restringir e determinar o seu desempenho e a sua capacidade de obter uma maior rentabilidade.

Alguns autores mostram estudos relacionados ao gargalo na produção industrial dentre os quais citam-se [22][24][25][13], afirma: Para o processo produtivo, o gargalo é a etapa com menor capacidade produtiva e que impede a empresa em atender plenamente a demanda por seus produtos. Por outro lado, a existência de níveis excessivos de capacidade produtiva em algumas etapas não-gargalos em relação à etapa gargalo, resultam em investimentos ociosos, que influenciam negativamente o desempenho da empresa. Assim, aumentar a capacidade produtiva da etapa gargalo e/ou redimensionar os investimentos ociosos nas etapas não-gargalos, podem constituir decisões estratégicas capazes de promover um maior retorno sobre o investimento.

Em um processo produtivo quando a capacidade produtiva e maior que a produtividade não existe a possibilidade de ter gargalo na produção e em todas as etapas da produção existem níveis que podem ser excessivos em todas as etapas. Em uma empresa, este fator pode ser primordial para a maior rentabilidade da mesma [38].

Para [26] a empresa deve focar nos recursos gargalos: Uma hora perdida num recurso gargalo é uma perdida em todo o sistema produtivo: como os recursos gargalos não possuem tempos ociosos, caso algum problema venha a acontecer com estes recursos, a perda de produção repercutirá em todo o sistema, reduzindo o fluxo.

Para [15] definem que "Gargalo é qualquer recurso cuja capacidade é igual ou menor que a demanda de mercado imposta sobre ele". Portanto, conforme argumenta o autor, o gargalo aparece quando o mercado exige dele uma demanda maior que sua capacidade para atender.

\section{II.7 CRONOANÁLISE/TEMPO}

Nesse âmbito o surgimento de uma ferramenta relevante no âmbito fabril, o estudo dos tempos e movimentos dando origem a cronoanálise, que tem como principal objetivo em conhecer detalhadamente o processo, evitando desta forma fadigas, estresse minimizando tempos ociosos em máquinas e operadores, e detectando pontos falhos a serem otimizados.

Entretanto é necessária a realização de estudos de tempos produtivos, com análises que sugerem métodos adequados e racionais, e avaliação de processos de produção com redução de movimentos inúteis e desnecessários para o colaborador.

A cronoanálise apresenta-se como o método utilizado para cronometrar e realizar análises do tempo que um operador leva para realizar uma tarefa no fluxo produtivo, permitindo um tempo de tolerância para as necessidades fisiológicas, possíveis quebras de maquinários, entre outras.

O surgimento da cronoanálise partiu dos estudos de Taylor e dos Gilbreth. Para tanto Taylor enfatiza a divisão das operações e a real capacidade do operador, enquanto Gilbreth refere-se aos movimentos e os aspectos ligados à fadiga e à economia dos movimentos desnecessários, tendo como principio estabelecer os tempos padrões para o desempenho no trablaho, sendo que estes incluem tolerâncias para pausa e descanso. $\mathrm{O}$ uso da cronoanálise é indicado quando há necessidade de melhorar a produtividade, reduzir os tempos e entender detalhadamente o que ocorre no processo produtivo.

Para tanto [27] compreende a existência de dois modos de determinação do tempo padrão. Um deles utiliza a cronometragem e chama-se cronoanálise. Outro modo trata de tempos pré-determinados para os movimentos desenvolvidos na operação. Onde o primeiro modo é um dos mais utilizados atualmente.

A partir da cronoanalise é possível identificar os pontos ineficientes do processo, bem como os desperdícios de tempo. De modo que facilita a realização de estudo de melhoria de processos e o aumento da produtividade.

Partindo desta conjuntura a cronometragem é uma ferramenta que evidência os pontos relevante para uma amostragem de tempos. Para o mesmo autor podemos elencar os pontos:

cronometragem:

- Real capacidade do operador para a

- Número de medições exigidas para uma análise confiável:

- Avaliação de tolerância em porcentagem para cada operação.

Dentro desta perspectiva, o referido autor considera a cronoanálise como a base para a racionalização da produção, do espaço físico, do maquinário e do capital humano.

\section{II.8 TEMPO, MÉTODOS E MOVIMENTOS}

A determinação do tempo padrão permite a análise da capacidade produtiva de um determinado processo considerando todos os aspectos que têm impacto no tempo necessário para a fabricação de um produto. 
Encontra-se nos princípios e conceitos da administração cientifica, visando o aumento dos níveis de produtividade a partir da racionalização do trabalho.

A determinação do tempo utilizado desenvolvido em uma operação realizar-se-á considerando condições normais de trabalho. Este tempo é um referencial a ser adotado no treinamento de novos funcionários para o manuseio no processo produtivo, chamado tempo-padrão, necessário para executar uma operação com o método estabelecido, em determinada condição, por operador apto e treinado, com habilidade e esforço médio durante todas as horas do Serviço. Para determinar o tempo padrão (TP), é necessário realizar o estudo do tempo normalizado as tolerâncias definidas para a operação de acordo com as equações.

Equação para identificação da quantidade de ciclos a serem cronometrados onde consiste em:

$$
N=\frac{Z \cdot R}{E r \cdot D 2 \cdot \bar{X}}
$$

Onde:

$\mathrm{N}=$ número de ciclos a serem cronometrados;

$\mathrm{Z}=$ coeficiente de distribuição normal para uma probabilidade determinada

$\mathrm{R}=$ amplitude da amostra;

$\mathrm{Er}=$ erro relativo da medida;

$\mathrm{D}_{2}=$ coeficiente em função do número de cronometragens realizadas preliminarmente;

$\bar{X}$ é a média dos valores das observações.

Para a utilização da expressão, deve-se realizar uma cronometragem prévia, cronometrando-se a operação entre cinco e sete vezes e retirando-se dos resultados obtidos a média e amplitude R. Devem também ser fixados os valores das probabilidade e do erro relativo que são desejados. Na prática, costumam-se utilizar probabilidades entre $90 \%$ e $95 \%$, e erro relativo entre $5 \%$ e $10 \%$.)

Após os dados do estudo de tempos terem sido obtidos, é realizada a determinação do tempo normal (TN) e tempo padrão (TP) dos elementos. Conforme a representatividade das equações (2) e (3).

$$
\mathrm{TN}=\mathrm{TCx} \mathrm{V}
$$

Onde:

$\mathrm{TN}=$ Tempo normal

$\mathrm{TC}=$ Tempo cronometrado

$\mathrm{V}=$ Velocidade média do operador

Equação para obtenção do tempo padrão (TP) onde consiste em:

$$
\mathrm{TP}=\mathrm{TNxFT}
$$

$\mathrm{TP}=$ Tempo padrão

$\mathrm{TN}=$ Tempo normal

FT= Fator de tolerância

Quanto ao tempo a determinação normal é definido por [28] como sendo o processo de análise da velocidade com que o trabalhador realiza suas atividades com desempenho-padrão, o estudo de tempos através da cronoanálise é uma forma de medir e controlar estatisticamente a tarefa a ser realizada, calculando o tempo. [13] define tempo padrão - TP como a capacidade produtiva da organização que ainda engloba fatores como velocidade do operador para execução da tarefa e seu rendimento com tolerâncias em porcentagem, fadiga do operador, e ainda as necessidades peculiares do operador.

No que concerne aos estudos de tempos [28], considera a cronometragem do tempo necessário para a realização de uma atividade desenvolvida. E compreende o tempo como:

$\mathrm{O}$ estudo de tempos movimentos e métodos de trabalho continua tendo papel central na determinação da produtividade. Reproduz o que foi determinado é um dos principais fatores de julgamento da qualidade de um funcionário, e fator importante para determinar sua permanência na organização [28].

Neste sentido a cronoanálise é desenvolvida nas empresas pra mensurar o tempo padrão de cada etapa do processo.

Utilizando a estatística para alcançar valores exatos quanto ao tempo das tarefas executadas, tendo como finalidade propor métodos de otimização na realização das tarefas, proporcionando a padronização necessária para o balanceamento do processo produtivo e para determinação da capacidade produtiva da empresa. Para [12] comenta que o estudo de tempos e movimentos é a análise dos métodos, tempos, materiais, ferramentas e instalações que irão ser utilizadas na execução do trabalho. Correlacionamos a relação do tempo uma mensuração do trabalho efetivado nas empresas

No que tange a Concessão das tolerâncias consideramos que o tempo normal da operação não possui tolerância; ele é o tempo que o operador precisa para realizar a operação trabalhando em ritmo normal. Haja vista as ocorrencias de interrupções para descansos, e principalmente as peculiaridades pessoais relacionadas a outros motivos que podem ser classificadas em interrupções tais como: tolerância para fadiga, tolerância para pessoal ou tolerância de espera.

Conforme o tempo padrão, ao contrário do tempo normal, a duração de todos os elementos e os tempos de todas as tolerâncias necessárias durante a operação, ou seja, é o tempo normal mais as tolerâncias. A descrição das classificações de tolerâncias apresentadas por [22]:

- Tolerância pessoal: O operário tem direito a um tempo reservado para suas necessidades pessoais, por isso devem estar em primeiro lugar. Em uma jornada de trabalho de 8 horas diárias, o trabalhador usará cerca de $2 \%$ a $5 \%$ por dia para tempo pessoal, variando com a tolerância pessoal do indivíduo.

- Tolerância para fadiga: O consumo de energia ocorre por meio do esforço empregado pelo trabalhador durante seu dia de trabalho.

- Tolerância para espera: As esperas podem ser evitáveis ou inevitáveis. As esperas realizadas de modo intencional pelo operador são as evitáveis e não são consideradas para determinação do tempo-padrão. As inevitáveis são aquelas advindas de ajustamentos ligeiros, quebras de ferramentas ou interrupções pelos supervisores.

Conforme [29], as atividades a serem realizadas devem contar com a disposição dos trabalhadores. Sendo assim, o esforço muscular constante, a realização de atividades repetitivas em tempo integral e a concentração extrema poderão causar fadiga às pessoas. 
O que é fadiga? Para os fisiologistas é um complicado fenômeno de intoxicação dos tecidos. Para o cronotécnico é simplesmente o efeito do trabalho sobre o organismo do operador, tendo como consequência a diminuição progressiva de sua capacidade de produção.

Nas primeiras horas, o ritmo de trabalho tende a aumentar, e após algumas horas há um declínio no rendimento devido à predominância da fadiga. Dentro desta perspectiva o operador apresenta suas necessidades fisiológicas, sendo necessário um tempo destinado durante a jornada de trabalho, resultando em um melhor rendimento produtivo. Que permite observar a priori uma redução progressiva na capacidade produtiva do operador resultante da fadiga sobre o organismo ao longo do dia.

Quanto aos métodos de cronoanálise consideramos que é à base da racionalização da produção, do espaço físico, do maquinário e do capital humano. No que concerne aos métodos podemos avaliar com outros conceitos utilizados na análise dos métodos de cronoanálise, não apenas para descobrir um padrão de referência, mas serve para uma determinação econômica do processo.

A Cronoanálise analisa os métodos, materiais, ferramentas e instalações utilizadas para a execução de um trabalho com o objetivo de encontrar uma forma mais econômica de se fazer um trabalho, normalizar os métodos, materiais, ferramentas e instalações, determinar de forma exata e confiável o tempo necessário para um empregado realizar um trabalho em ritmo normal (tempo padrão) [30].

Para [29], "Cronometria é o cálculo, o ato mecânico de se chegar ao Tempo padrão. Cronoanálise é a tabulação, é a arte de utilização do tempo padrão, visando a melhoria no método de trabalho" e relevante ressaltar claramente a importância da cronoanálise na indústria, profissionalmente e na vida prática.

Analisando os dados do estudo de tempos e movimentos realizado por Barnes citados anteriormente. Souza desenvolveu um método semelhante, entretanto mais prático e fácil de ser aplicado nas empresas.

A análise dos estudos de Barnes permitiu gerar uma folha de cronoanálise eletrônica, que permite ao observador eliminar a realização dos cálculos, necessitando apenas o preenchimento da planilha com os dados do processo, excluindo o tempo necessário para a realização dos cálculos.

Deste modo, a aplicabilidade do método de cronoanálise desenvolvido por Souza consiste no preenchimento da planilha e na avaliação dos resultados obtidos, isso justifica que a utilização de uma folha de cronoanálise eletrônica, além de ser prática, tornando o processo com uma celeridade e eficiente, bem como o aumento da confiabilidade do processo.

\section{II.9 ERGONOMIA}

De acordo com [31] a publicação "De Morbis Artificum" (Doenças ocupacionais) em 1700, pelo médico italiano Bernardino Ramazzini (1633-1714), foi o primeiro a descrever a respeito de lesões relacionadas ao trabalho. Ramazzini visitava os locais de trabalho dos seus pacientes com a finalidade de identificar as causas de seus problemas.
A termologia ergonomia foi introduzido pela primeira vez em 1857 pelo polonês Woitej Yastembowky. Em sua publicação intitulado "Ensaios de ergonomia ou ciência do trabalho, baseado nas leis objetivas da ciência sobre a natureza" [32].

A ergonomia está diretamente ligada ao ambiente de trabalho, que é caracterizado pelo espaço físico que abrange o colaborador e a efetivação de suas atividades. Compreende que o ambiente é entendido como espaço fisicamente determinado e especializado para o desenvolvimento de determinadas atividades caracterizadas por dimensões e instalações diferenciadas. A ergonomia difere de outras áreas do conhecimento pelo seu caráter interdisciplinar e pela sua natureza aplicada. O caráter interdisciplinar significa que a ergonomia se apoia em diversas áreas do conhecimento humano. Já o caráter aplicado configurase na adaptação do posto de trabalho e do ambiente às características e necessidades do trabalhador.

De acordo com [33], a ergonomia visa inicialmente à saúde, segurança e satisfação do trabalhador e, que podem ser assim descritas:

- $\quad$ Saúde - mantém-se a saúde do trabalhador a partir do momento em que não são ultrapassadas as limitações energéticas e cognitivas das exigências do trabalho e do ambiente.

- Segurança - obtida através de projetos do posto de trabalho, ambiente e da sua organização, desde que dentro das limitações e capacidades do trabalhador, permitindo reduzir acidentes, estresse, erros e fadiga.

- Satisfação - é o resultado referente ao atendimento das necessidades e expectativas do trabalhador.

Conforme [34], em projetos de trabalho e em situações cotidianas, a ergonomia enfoca o homem, na busca da adaptação de suas capacidades e limitações físicas e psicológicas em relação à eliminação das condições de insegurança, desconforto, ineficiência e insalubridade. Para tanto a ergonomia estuda vários aspectos, de acordo com [34] dentre os quais destacam-se:

- Postura e movimentos corporais, os quais podem ser assim relacionados - sentados, em pé, puxando e levantando cargas, empurrando.

- Fatores ambientais - evidenciados através de ruídos, vibrações, iluminação clima e agentes químicos.

- Informação, captadas por meio da audição, visão e demais sentidos.

A ergonomia também aborda conhecimento de diferentes áreas científicas, como a antropometria, biomecânica, toxicologia, engenharias, etc.

\section{MATERIAIS E MÉTODOS}

Esta pesquisa foi realizada em uma empresa do PIM no setor de manufatura de receptores digitais. A referida pesquisa tem o âmbito qualitativa e quantitativa com o foco em otimização do processo de testes de receptores TV digital.

Os dados foram reunidos no setor produtivo de receptor digital, através do estudo de tempos. A cronoanalise foi o instrumento fundamental para esta coleta de dados mensurando os tempos. Com o auxílio de um formulário de anotações para registrar os tempos dos testes de receptores. Dentre os procedimentos foi elaborado um questionário para obter a opinião 
dos colaboradores referente ao dispositivo implantado no processo de testes.

$\mathrm{Na}$ avaliação do processo atual, as conexões dos cabos, HDMI, RCA, cabo de alimentação elétrica e conector USB eram realizadas de forma manual, criando no posto de teste um risco ergonômico pois a pegada do colaborador nos cabos é realizada como uma pinça elevando o esforço da mesma. E contudo tornando o posto um gargalo no processo [35][36][37], Conforme figura 2 .

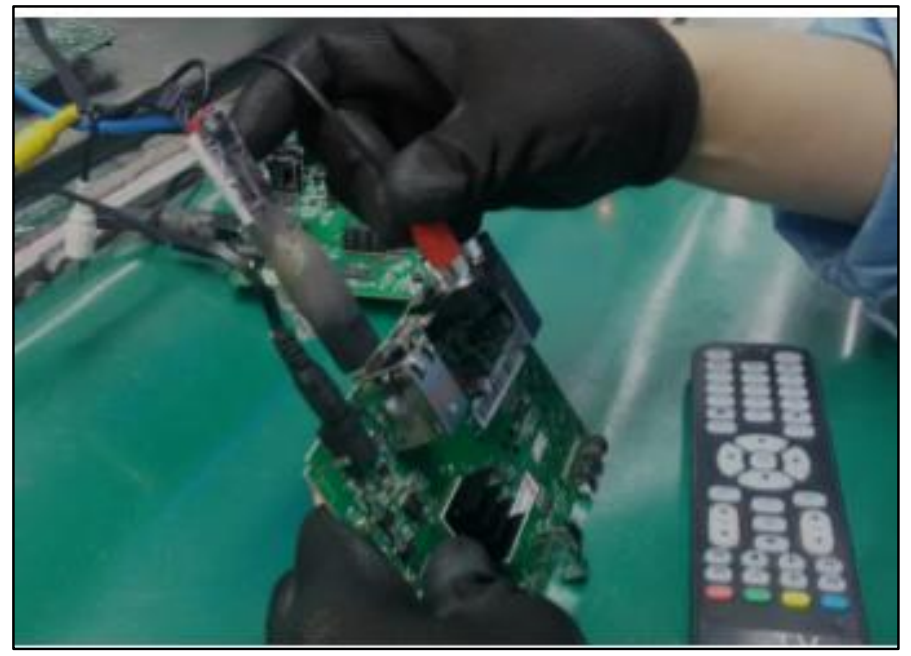

Figura 2: Conexão dos cabos manualmente.

Fonte: Autores, (2016).

O processo anterior a implantação do dispositivo encontrava-se da seguinte forma, o colaborador efetuava a conexão dos cabos manualmente para realizar o teste do receptor digital, com isso o tempo estimado para realizar as conexões é considerado elevado na atual conjuntura. Como demonstra o fluxograma 1, que mostra o passo a passo do processo atual. Passo 1, pegar placa de circuito impresso da esteira. Passo 2, conectar o cabo de alimentação elétrica. Passo 3, conectar o passo HDMI. Passo 4, conectar o cabo RCA. Passo 5, conectar cabo USB. Passo 6, efetuar o teste da Placa. Passo 7, desconectar o cabo de alimentação elétrica. Passo 8, desconectar cabo RCA. Passo 9, desconectar cabo RCA. Passo 10, Desconectar Cabo USB. Passo 11, posicionar placa na esteira. Passo 12, Posto de conserto e o último passo, Estoque de placas não conforme, onde não atende as especificações: sem áudio, sem vídeo, sem alimentação elétrica. A figura 3 mostra através do fluxograma, os passos de teste no setor.

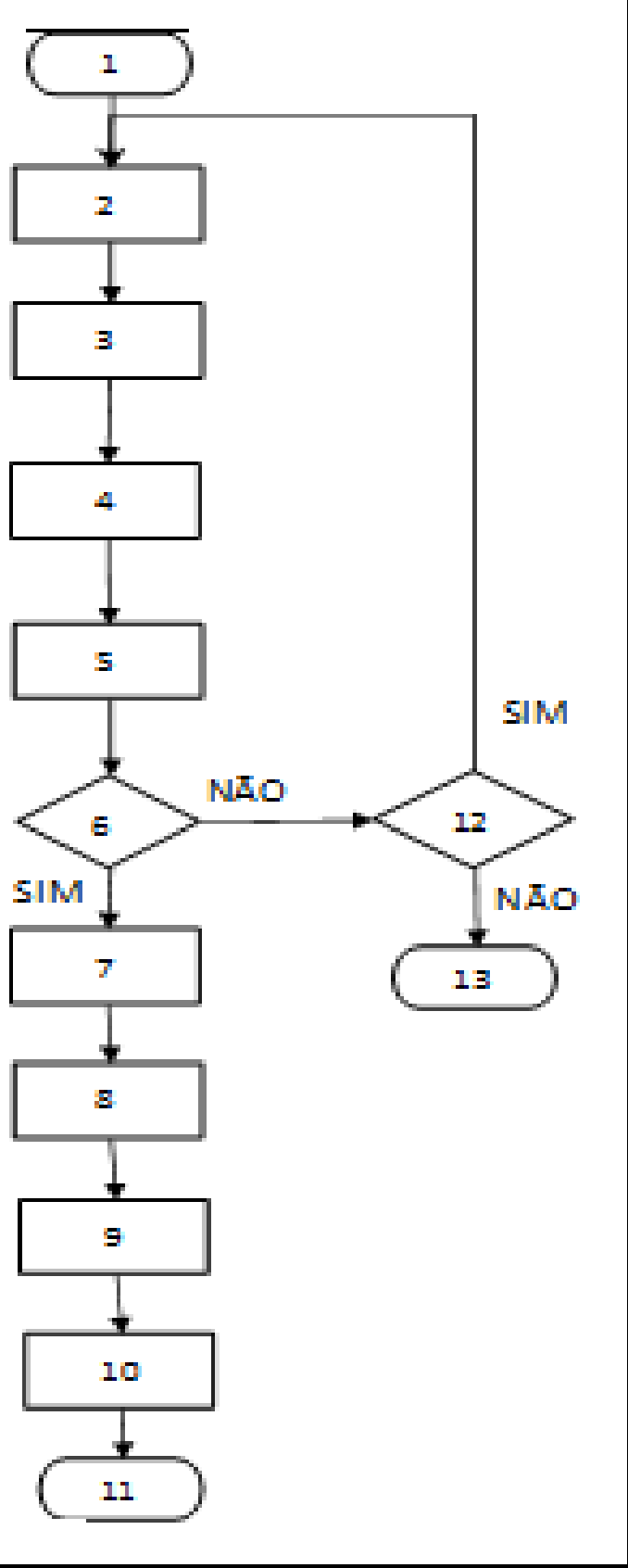

Figura 3: Fluxograma de operação de teste. Fonte: Autores, (2016). 
A figura 4 mostra detalhadamente o método manual sendo realizado por um colaborador da empresa. Onde as placas de circuito impresso ficavam sobre a bancada de teste.

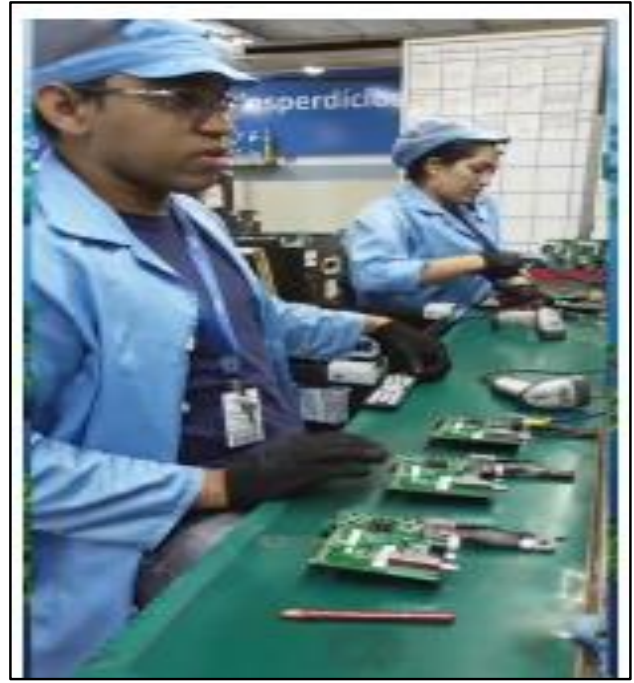

Figura 4: Linha de Teste da empresa.

Fonte: Autores, (2016).

Foram observados que esse método de teste manual excedia o tempo padrão do processo sendo necessário a multiplicação do posto de teste. Por outro lado, o movimento repetitivo manual ocasionava nos colaboradores desse setor doenças ocupacionais, dentre as quais pode-se citar: Túnel do carpo e bursite entre outras. Criando a necessidade da implementação de um dispositivo que facilitasse o processo de teste dos receptores digitais, minimizando o tempo de teste, maximizando a produção do setor e proporcionando melhoria com relação a ergonomia dos colaboradores.

\section{IV.ESULTADOS E DISCUSSÕES}

Com base nas informações supracitadas, foram realizados estudos para a otimização do processo, com o enfoque de reduzir o número dos movimentos do colaborador para efetuar a conexão dos cabos para a realização do teste funcional do receptor digital.

Após as análises e testes realizados o melhor método encontrado para efetuar as conexões dos cabos foi a confecção de um dispositivo, onde os cabos a serem conectados fiquem fixos na posição correta em um suporte" e uma base móvel em formato de uma "gaveta", onde a placa será assentada para a execução do teste, reduzindo assim o número de movimentos do colaborador e minimizando o tempo do teste funcional do receptor digital.

Segue o "Croqui" do projeto do dispositivo de teste, conforme figura 5 .

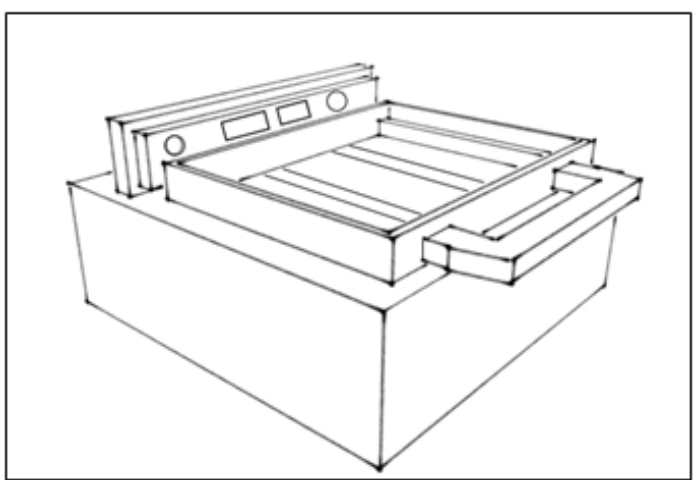

Figura 5: Croqui do projeto do dispositivo de teste. Fonte: Autores, (2016).

Conforme o projeto apresentado a empresa na qual foram realizadas a pesquisa onerando o ônus para a referida empresa.

O dispositivo de teste foi desenvolvido com o objetivo de otimizar o tempo de teste de receptor digital com ajustes na disposição de equipamentos, pessoas, distribuição de espaço quanto a sua ergonomia entre outros, e principalmente no sentido que venha garantir a máxima utilização dos recursos do processo, evitando a restrição quanto sua fluidez, buscando o fluxo continuo acelerando a transformação de matéria primas no produto final.

O referido equipamento foi confeccionado com o auxílio de uma empresa especializada em desenvolvimento de testes industriais.

A figura 6, mostra o dispositivo de teste após a implementação na linha de produção na qual cada posto de teste funcional efetua o teste de duas placas concomitantemente.

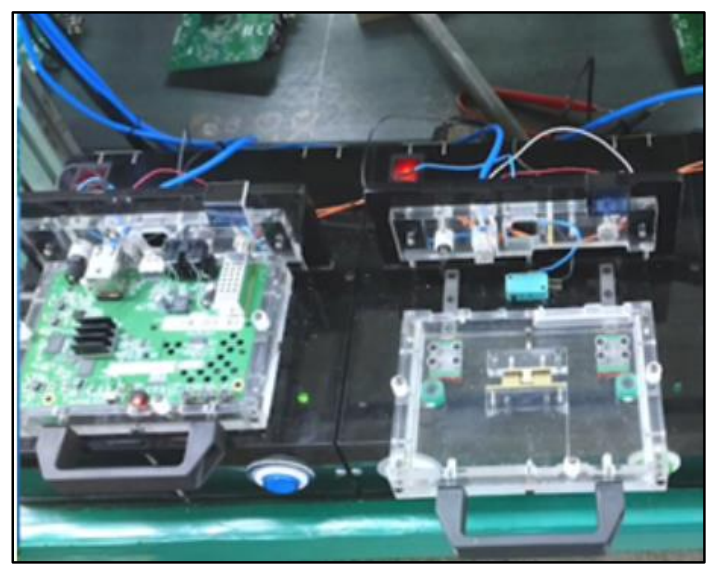

Figura 6: Bancada de dispositivo de Teste dos Receptores Digitais. Fonte: Autores, (2016).

De acordo com a figura 7 do fluxograma 2 do processo após a implementação do dispositivo analisou-se uma melhoria na capacidade produtiva que permite o aumento da eficiência no processo em virtude da quantidade reduzida de movimentos realizados pelo colaborador para efetivar o teste no receptor digital. 


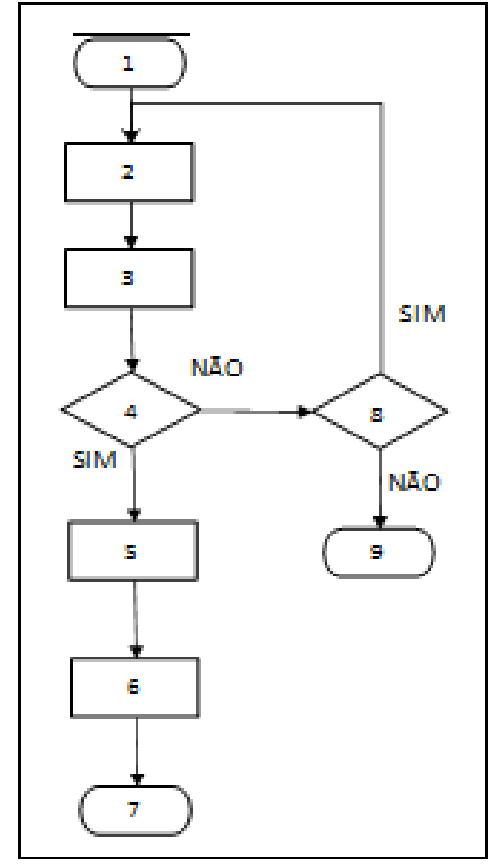

Figura 7: Fluxograma de operação de teste. Fonte: Autores, (2016).

Tende a diminuir os custos de produção por meios da eliminação de desperdício, minimizando as perdas. O fluxograma supracitado descreve o processo de teste após a implantação do dispositivo. Passo 1: retirar a placa de circuito impresso da esteira. Passo 2: posicionar PCI no dispositivo. Passo 3: empurrar gaveta do dispositivo para efetuar as conexões dos cabos. Passo 4: efetuar deste do produto Passo 5: puxar a gaveta para desconectar os cabos Passo 6: retirar a placa do dispositivo. Passo 7: posicionar a placa na esteira de produção. Passo 8: posto de concerto. Passo 9: estoque de placas não conforme.

A figura 9 mostra o tempo de teste nas três linhas de teste da empresa.

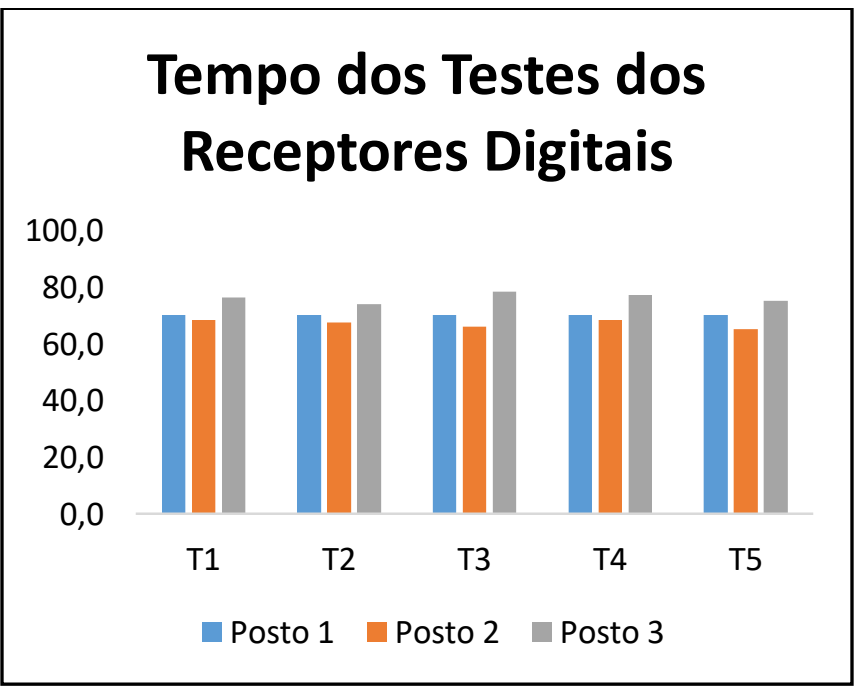

Figura 8: Tempo dos testes dos Receptores Digitais. Fonte: Autores, (2016).
A figura 9 mostra o tempo médio dos testes antes da implementação do dispositivo, observa-se que o terceiro posto de teste gasta aproximadamente 76 segundos para realizar o teste.

\section{Média do Tempo de Teste (Antes)}

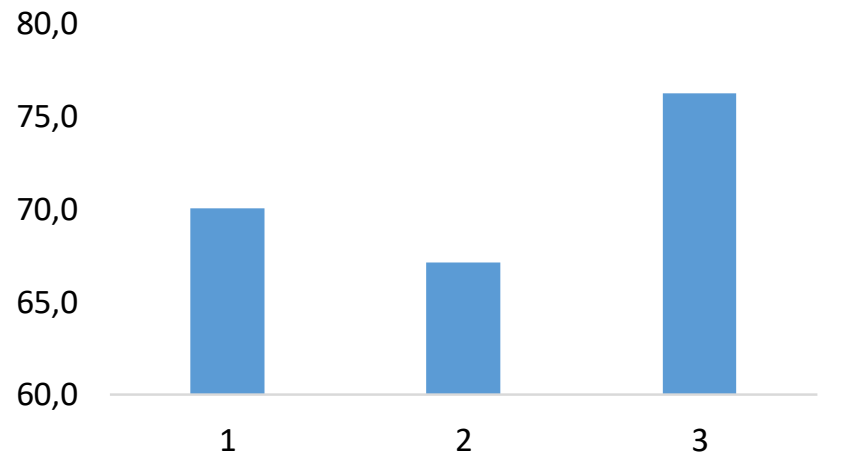

Figura 9: Tempo médio dos testes dos Receptores Digitais, antes da implementação do dispositivo.

Fonte: Autores, (2016).

A figura 10 mostra o tempo médio de teste após a implementação do dispositivo, nessa observa-se que o tempo de teste diminui de 70 para 35 segundos no primeiro posto de teste e de 66 para 36 segundos no segundo posto. Nesse gráfico observase que o terceiro posto de teste não está sendo exibido no gráfico. A explicação para este fato é dado em função da produção da empresa, pois os três postos de testes deveriam suprir a necessidade de testar 2000 receptores digitais Com a implementação do dispositivo o tempo de dois postos de testes foram suficiente para atender a meta da empresa.

\section{Tempo Médio (Após)}

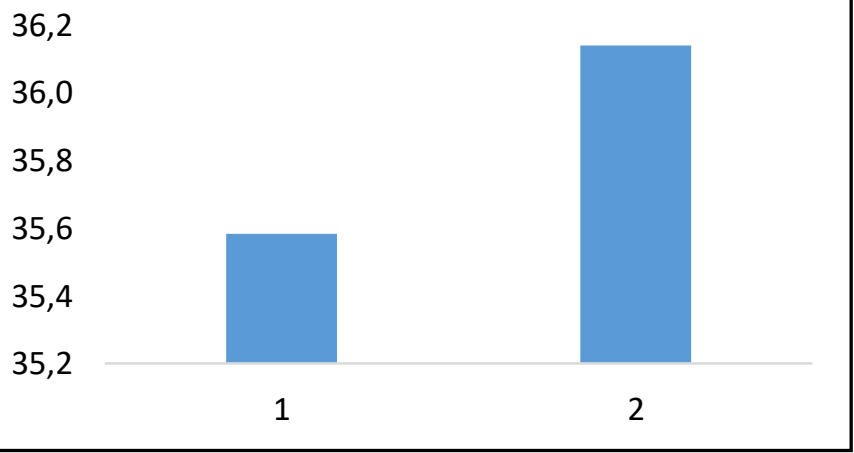

Figura 10: Tempo médio dos testes dos Receptores Digitais, antes da implementação do dispositivo.

Fonte: Autores, (2016).

A figura 11 mostra a comparação dos postos de testes após a implementação do dispositivo. 


\section{Teste dos Receptores Digitais ( DEPOIS)}

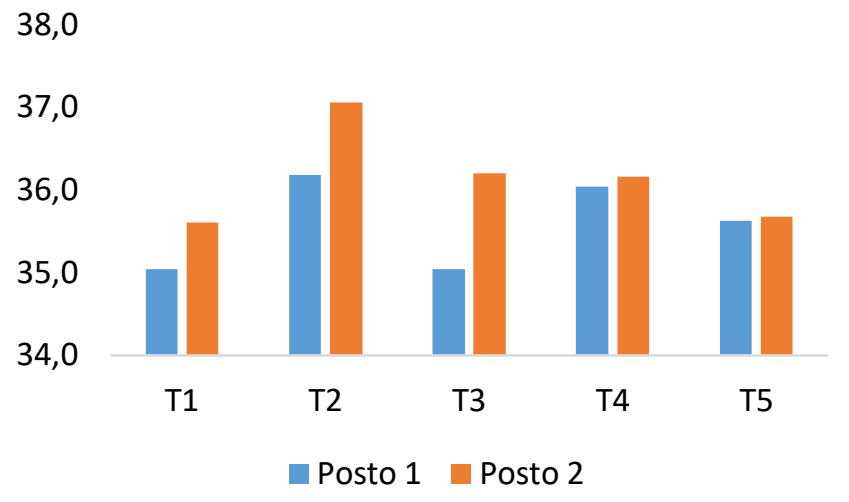

Figura 11: Tempo médio dos testes dos Receptores Digitais, após a implementação do dispositivo.

Fonte: Autores, (2016).

Observa-se que o primeiro posto desempenha melhor tempo para testar os dispositivos digitais comparados com o segundo posto. No primeiro momento de observação o primeiro posto de teste gasta 35 segundos para realizar o teste fazendo uma comparação com o posto antes da implementação do dispositivo observa-se que o tempo foi otimizado em $50 \%$ para este posto de teste e o tempo do posto 2 foi otimizado em $51 \%$. Analisando o mesmo pode-se comentar sobre a otimização do tempo de teste dos demais posto da empresa, que em média foi reduzido para $50 \%$ [39][40].

Para melhor visualização dos resultados a figura 12 mostra um comparativo entre os setores de teste antes e depois da implementação do dispositivo. Nessa figura 12 fica claro a otimização do tempo no teste dos dispositivos nos postos de testes 1,2 e 3 .

\section{Comparação dos tempos de Testes}

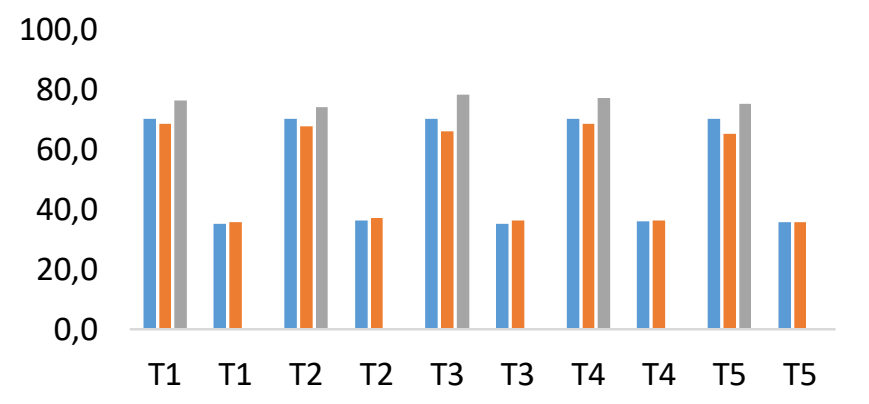

Figura 12: Comparação do Tempo testes dos Receptores Digitais, antes e após a implementação do dispositivo.

Fonte: Autores, (2016).

\section{CONCLUSÃO}

Este estudo possibilitou uma perspectiva na otimização do processo em uma empresa de fabricação em receptor digital no PIM, tendo em vista a necessidade da maximização da produtividade e principalmente no aumento de custo benefício para a empresa na qual foram realizados um estudo de caso, utilizando pesquisas sobre otimização, produtividade, cronoanálise, e ergonomia, desenvolvendo um elo entre capacidade operacional e montagem dos componentes por meio de implementação do dispositivo de teste em receptor digital, possibilitando verificar as necessidade de melhoria no processo ergonômico através de analises na cronoanálise, através da divisão de operações, onde a produção em série depende consideravelmente do alto rendimento, habilidades e destreza dos colaboradores.

Foram observados que esse método de teste manual excedia o tempo padrão do processo sendo necessário a multiplicação do posto de teste. Por outro lado, o movimento repetitivo manual ocasionava nos colaboradores desse setor doenças ocupacionais, dentre as quais pode-se citar: Túnel do carpo e bursite entre outras. Criando a necessidade da implementação de um dispositivo que facilitasse o processo de teste dos receptores digitais, minimizando o tempo de teste, maximizando a produção do setor e proporcionando melhoria com relação a ergonomia dos colaboradores.

Com base nas informações supracitadas, foram realizados estudos para a otimização do processo, com o enfoque de reduzir o número dos movimentos do colaborador para efetuar a conexão dos cabos para a realização do teste funcional do receptor digital. Após as análises e testes realizados o melhor método encontrado para efetuar as conexões dos cabos foi a confecção de um dispositivo, onde os cabos a serem conectados fiquem fixos na posição correta em um suporte" e uma base móvel em formato de uma "gaveta", onde a placa será assentada para a execução do teste, reduzindo assim o número de movimentos do colaborador e minimizando o tempo do teste funcional do receptor digital.

É notório observar a diferença entre o processo manual e o processo após a implantação do dispositivo de teste. Tendo em vista que o tempo estimado para o teste foi reduzido significativamente, diminuindo os movimentos, ganhando em tempo de processo, aumentando o fluxo de placas no posto, reduzindo a fadiga do colaborador e possibilitando a execução do teste em apenas dois postos tendo em vista que antes a implantação do dispositivo era necessário três postos de testes para atender o tempo padrão da linha de processo.

Os objetivos de otimizar o tempo de teste dos receptores digitais, foram alcançadas com redução de 50\% do tempo.

\section{AGRADECIMENTOS}

Ao programa Bolsa Universidade pelo incentivo financeiro. Ao Instituto de Tecnologia e Educação Galileo do Amazônia (ITEGAM) e ao Centro Universitário do Norte (UNINORTE) incentivo a pesquisas na região Norte. 


\section{VII.REFERÊNCIAS}

[1] Villarouco, V. and L. F. Andreto (2008). "Avaliando desempenho de espaços de trabalho sob o enfoque da ergonomia do ambiente construído." Produção 3(18): 523-539.

[2] Rufino, S. (2006). "A contribuição da Engenharia de Produção para a Economia Solidária." XIII SIMPEP.

[3] De Souza Limaa, V. B., P. P. Balestrassib and A. P. de Paivac (2010). Otimização do desempenho de amplificadores de radiofrequência banda larga: uma abordagem experimental, SciELO Brasil.

[4] Menezes de Carvalho, G. and R. Dutra de Moraes (2011). "Sobrecarga de trabalho e adoecimento no Polo Industrial de Manaus." Psicologia em Revista 17(3): 465-482.

[5] Miguel, P. A. C. (2007). "Estudo de caso na engenharia de produção: estruturação e recomendações para sua condução." Revista Produção 17(1): 216-229.

[6] Pereira Desenvolvimento e crise no Brasil (BRESSERPEREIRA, 2003 [1968], p. 168-178)

[7] Brum, Argemiro J. O Desenvolvimento Econômico Brasileiro. 29. ed. Petrópolis, RJ: Vozes; Ijuí, RS: Unijuí, 2012. ISBN: 978857429-966-2

[8] Salazar, Admilton Pinheiro. Amazônia Globalização e Sustentabilidade. Manaus: Editora Valer, 2006.

[9] Chiavenato, Idalberto. Comportamento organizacional: a dinâmica do sucesso das organizações. Editora Manole, 2005.

[10] KUPFER, D. Trajetórias de reestruturação da indústria brasileira após a abertura e a estabilização. 1998. Tese (Doutorado) - IE/UFRJ.

[11] Quadros, R. et al. Technological innovation in brazilian industry: an assessment based on the São Paulo innovation survey. Technological forecasting and social change. Edição especial sobre technology policy and innovation for ghe globalized learning economy [s. 1.]: [s. n.], 1999.

[12] Toledo Jr, Itys Fides Bueno e KURATOMI, Shoei. Cronoanálise base da racionalização, da produtividade da redução de custos. 3. ed. São Paulo: Itysho, 1977

[13] Martins, P. G. and F. P. Laugeni (2009). Administração da produção, Saraiva.

[14] Lima, Larissa Carvalho de. Aplicação de ferramentas de qualidade para solução de problemas no processo produtivo com ênfase nos princípios da produção enxuta. 2016.

[15] Goldratt, E. M. \& COX, J. - A Meta - Um processo de aprimoramento contínuo, São Paulo, 12ed, 2002.

[16] Araújo, C. A. C. Desenvolvimento e aplicação de um método para implementação de sistemas de produção enxuta utilizando os processos de raciocínio da teoria das restrições eo mapeamento do fluxo de valor, 2004.

[17] Klippel, A.F. - Estratégia de gestão dos postos de trabalho Um estudo de caso na indústria de alimentos. Artigo publicado no XIII Encontro Nacional de Engenharia de Produção (ENEGEP), Ouro Preto,2003.

[18] Womack, J.P.; Jones, D. T. A mentalidade enxuta nas empresas: elimine o desperdício e crie riquezas. 5. ed. Rio de Janeiro: Campus, 2004.

[19]Ghinato, P. Elementos Fundamentais do Sistema Toyota de Produção. Produção e Competitividade: Aplicações e Inovações. Ed. Almeida \& Souza, Editora Universitária da UFPE, Recife, 2000.

[20] Moreira, D. A. Administração da Produção e Operações. 2 ed. São Paulo: Cengage Learning, 2008.

[21] Sanches, Alexandre Leme. Sequenciamento de linhas de montagem múltiplas em ambiente de produção enxuta utilizando simulação. 2010.

[22] Slack, N., S. Chambers and R. Johnston (2009). Administração da produção, Atlas.

[23] Saurin, T. A.; Ferreira, C. F. Avaliação qualitativa da implantação de práticas da produção enxuta: estudo de caso em uma fábrica de máquinas agrícolas. Gestão e Produção, v. 15, n. 3, p. 449-462, 2008

[24] Rigon, G. D. P. (2015). "Gargalos de produção: estudo de caso na JBS Alves unidade de Passo Fundo/RS."

[25] PESSOA, P. (,2003). "PFA de. (2003). Gestão Agroindustrial." Fortaleza: Embrapa Agroindústria Tropical.

[26] Tubino, Dalvio Ferrari. Planejamento e controle da produção. 2. ed. São Paulo: Atlas, 2009.

[27] Baraldi, E.C. Ergonomia e abastecimento planejado em uma linha de montagem automotiva. 2006. Dissertação (Mestrado em Engenharia Automotiva) - Escola Politécnica da Universidade de São Paulo, São Paulo, 2006.

[28] Peinado, Jurandir; Graeml, Alexandre Reis. Administração da produção. Operações industriais e de serviços. Unicenp, 2007.

[29] Bortoli, Henrique Weber. "Aplicação da cronoanálise para melhoria do processo de suprimento da linha de montagem de uma empresa de grande porte do ramo agrícola." (2013).

[30] Miranda, Douglas. Os conceitos de "tempo" na cronoanálise. Artigonal diretório de artigos gratuitos. Disponível em: http://www.artigos.com/artigos/engenharia/producao/osconceitosde-\%93tempo\%94-na-cronoanalise.-6389/artigo/ 
[31] Franceschi, Alessandro. Ergonomia. 2013. Disponível em < http://estudio01.proj.ufsm.br/cadernos_seguranca/quinta_etapa/er gonomia.pdf . Acesso em 24 outubro 2016.

[32]Barbosa Filho, A. N. Segurança do trabalho e gestão ambiental. São Paulo: Atlas, 2010.

[33] Iida, Itiro. Ergonomia: projeto e produção. 2. ed. São Paulo: Edgard Blücher, 2005.

[34] Dul, Jan \& Weerdmeester, Bernard. Ergonomia prática. Tradução por Itiro Iida. São Paulo: Edgar Blücher, 2004.

[35] Toledo Jr, Itys Fides Bueno. Produção, produtividade e eficiência. 8. ed. São Paulo: Raphael A.Godoy, 2004.

[36] Shingo, S. Sistemas Toyota de Produção: do Ponto-deVista da Engenharia de Produção. Tradução de Eduardo Schaan. Porto Alegre: Bookmann, 291p, 1996 .

[37]Shingo, S. Sistemas de Produção com estoque zero: 0 Sistema Shingo para melhorias contínuas. Tradução de Lia Weber Mendes. Porto Alegre: Bookmann, 380p, 1996 b.

[38] Pedro F. Adeodato de Paula Pessoa; José Ednilson de Oliveira Cabral. Identificação e análise de gargalos produtivos: impactos potenciais sobre a rentabilidade empresarial. 2010.

Pessoa, P. (,2003). "PFA de.(2003)-Gestão Agroindustrial." Fortaleza: Embrapa Agroindústria Tropical.

[39] Peroni, Wilson José, Manual de Tempos e Movimentos, 2 ed.Rio de Janeiro:Apex 1985

[40] Barnes, R. M. Estudos de movimentos e de tempos: projetos e medidas do trabalho. São Paulo: Edgard Blücher, 1977. 